\title{
Adenosarcoma cM0 TNM Finding v7
}

National Cancer Institute

\section{Source}

National Cancer Institute. Adenosarcoma cMO TNM Finding v7. NCI Thesaurus. Code C89630.

No distant metastasis. (from AJCC 7th Ed.) 